\title{
Informação e patrimônio cultural: uma definição jurídica de informação patrimonial
}

Rosilene Paiva Marinho de Sousa

Doutoranda em Ciência da Informação pela Universidade Federal da Paraíba, com Mestrado em Ciência da Informação pela Universidade Federal da Paraíba.Especialista em Direito do Trabalho e Processo do Trabalho pelo Centro Universitário de João Pessoa - UNIPÊ

Bernardina Maria Juvenal Freire de Oliveira

Professora adjunta da Universidade Federal da
Paraíba.Doutora em Letras pela Universidade
Federal da Paraíba.Mestre em Ciência da
Informação pela Universidade Federal da
Paraíba.Especialista em Organização de
Arquivos.Graduada em Biblioteconomia pela
Universidade Federal da Paraíba

Carlos Xavier de Azevedo Netto

Bolsista de Produtividade de Pesquisa do CNPq, nível 2.Graduado em Arqueologia pela Universidade Estácio de Sá Mestre em História e Crítica da Arte Doutor em Ciência da Informação pela Escola de Comunicação/IBICT.Professor Associado da Universidade Federal da Paraíba

http://dx.doi.org/10.1590/1981-5344/2345

Apresenta uma reflexão sobre os instrumentos jurídicos de amparo ao patrimônio cultural brasileiro. Desenvolve considerações sobre os diversos conceitos de informação e busca elaborar uma definição jurídica de informação patrimonial, e, a partir de então, realizar uma discussão buscando analisar aspectos que definem o patrimônio cultural imaterial. Do ponto de vista metodológico adotarse-á a técnica de análise de conteúdo na perspectiva de Bardin. Expõe comentários sobre possíveis barreiras ou viabilidade de uma ampliação do referido conceito.

Palavras-Chave: Instrumentos jurídicos; Patrimônio cultural; Informação - definição. 


\title{
Information and cultural heritage: a legal definition of patrimonial information
}

\begin{abstract}
Presents a reflection on the legal instruments of support to the Brazilian cultural heritage. Develops the concept of information considerations and seek to draw up a legal definition of patrimonial information, and, from then on, perform a discussion seeking to analyse aspects that define the intangible cultural heritage. From the methodological point of view will adopt the technique of content analysis in the perspective of Bardin. Exposes comments on possible barriers or feasibility of an expansion of that concept.
\end{abstract}

Keywords: Legal instruments; Cultural heritage; Information - definition.

Recebido em 01.03.2015 Aceito em 17.06.2015

\section{Introdução}

Nos últimos anos tem-se percebido uma relevante atenção dedicada pelos poderes instituídos ao patrimônio cultural brasileiro, cujo objetivo primordial seria a preservação dos bens culturais e sua transmissão a futuras gerações.

A pesquisa objeto deste artigo centra seu foco na análise de instrumentos jurídicos que protegem o patrimônio cultural brasileiro, tendo como fundamento a Constituição Federal de 1988 e o Decreto 3.551, de 4 de agosto de 2000 (BRASIL. Presidência da República, 2000), que instituiu o registro de bens culturais de natureza imaterial, tornando possível a proteção dos bens culturais de natureza intangível, incluindo as formas de expressão e os modos de criar, fazer e viver, levando-se em consideração os saberes, as celebrações e os lugares.

A presente proposta se alvitra a examinar os variados conceitos de informação e busca elaborar uma definição jurídica de informação patrimonial, realizando considerações sobre aspectos que definem o patrimônio cultural imaterial.

Neste sentido, expõe comentários sobre possíveis barreiras no decorrer da construção da definição do termo informação patrimonial, bem como destacar a possibilidade de ampliação do mesmo. 
A relevância desse artigo está na realização de uma contribuição a memória pátria, por tratar-se de tema pouco discutido, mas de caráter relevante nos estudos do patrimônio cultural.

\section{A proteção ao patrimônio cultural no Brasil}

Nos últimos anos a atenção dada ao patrimônio cultural brasileiro despertou entre juristas e doutrinadores contemporâneos o interesse nessa área. Diante dessa situação buscou-se delimitar o campo de atuação da proteção ao patrimônio cultural e sua determinação teórica, que será abordada nesta seção.

\subsection{Patrimônio cultural como direito fundamental e difuso}

A expressão direitos fundamentais (droits fondamentaux) surgiu na França, em 1970, no movimento político e cultural que deu origem à Declaração dos Direitos do Homem e do Cidadão, em 1789. Na Constituição Brasileira de 1988, os direitos fundamentais foram regulados nos arts. $1^{0}$ ao 17 , tendo a doutrina e a jurisprudência firmadas que 0 Supremo Tribunal Federal pode reconhecê-los em outras partes da Constituição.

Os direitos fundamentais são os direitos humanos consagrados e positivados na Constituição de cada país no plano interno, podendo o seu conteúdo e conformação variar de Estado para Estado (NOVELINO, 2010).

A proteção ao patrimônio cultural, no entendimento de Miranda (2006), está inserida no conceito de direito fundamental de terceira geração. Esta classificação é dada a partir de um enfoque histórico de acordo com as funções preponderantes por eles desempenhadas.

Neste sentido, a Primeira Dimensão denominada de Liberdade, conhecidos como direitos civis e políticos, seguindo a superveniência de interesses que foram capazes de ocasionar mudanças sociais, com as primeiras manifestações liberais surgiram com a burguesia, para limitar o poder do Estado absolutista. Têm caráter negativo, exigindo uma abstenção do Estado (direitos de defesa). O principal destinatário é o Estado. São direitos individuais que protegem o indivíduo em face do Estado.

A luta do proletariado, nas revoluções industriais (sociais, econômicas e culturais), tem como objetivo diminuir as desigualdades existentes, além da liberdade. Surge, então, a Segunda Dimensão, denominada de Igualdade.

Com a nítida divisão do mundo entre países desenvolvidos e em desenvolvimento (subdesenvolvidos), surgiu a necessidade de colaboração dos mais ricos com os mais pobres. Surge a Terceira Dimensão, denominada de Fraternidade ou solidariedade, (direito ao progresso, à autodeterminação dos povos, ao meio ambiente saudável, direito de propriedade sobre o patrimônio comum da humanidade, etc.), sendo 
considerados como direitos difusos, que pertencem a grupos indetermináveis de pessoas.

A Quarta Dimensão, apresentada por Paulo Bonavides, trata da influência da globalização política na esfera jurídica (direitos à democracia; informação e pluralismo político). No entendimento do renomado jurista, a democracia positivada há de ser, essencialmente, uma democracia direta, que se torna a cada dia mais possível, graças aos avanços tecnológicos dos meios de comunicação e sustentados legitimamente pela informação correta e aberturas pluralistas do sistema.

A mais recente, a Quinta Dimensão refere-se ao Direito à paz. Segundo Paulo Bonavides, encontra-se no art. 40, VI, da Constituição Federal (BRASIL. Constituição, 1988).

Foi na Constituição Federal de 1988 que se deu a regulação jurídica do patrimônio cultural brasileiro, os quais pertencem ao grupo dos chamados direitos difusos, em que materializam poderes de titularidade coletiva. Sarlet (1998, p. 135) coloca-os como integrantes da categoria de direitos "metaindividuais", em que indivisibilidade é a primeira característica, dado que são "de todos e (de) cada um, de cada um e de todos".

Os direitos difusos, conforme o artigo 81, parágrafo único, da Lei n. 8.078, de 1990 (BRASIL. Presidência da República, 1990), são os direitos considerados transindividuais (pertencem a um grupo, categoria ou classe de pessoas que tenham entre si um vínculo, de natureza jurídica ou fática), de natureza indivisível, de que sejam titulares pessoas indeterminadas e ligadas por circunstâncias de fato. Neste sentido, tornase possível verificar que apresentam três características fundamentais, a saber, a indivisibilidade do objeto, a indeterminabilidade do sujeito e a ligação dos mesmos por um vínculo fático e não jurídico.

Conforme Miranda (2006), a proteção ao patrimônio cultural satisfaz a humanidade como um todo, na medida em que preserva seus valores, assegurando a sua transmissão as gerações futuras. Desse modo, o patrimônio cultural pode ser reconhecido como um direito difuso, pois este objetiva a tutela de interesses pertencentes ao gênero humano, uma vez que pertence a todos ao mesmo tempo e não pertence, de forma individualizada, a qualquer pessoa. Benjamin (1995, grifo do autor), elenca os seguintes traços na apreciação dos direitos difusos:

a) a transindividualidade real ou essencial ampla e b) a indeterminação de seus sujeitos; na perspectiva da objetividade, c) a indivisibilidade ampla e d) a indisponibilidade; no campo relacional-jurídico, e) o vínculo meramente de fato a unir os sujeitos; no âmbito político, f) ausência de unanimidade social, dado fundamental para apartá-los do interesse público, e g) organização possível, mas sempre subotimal, traço este atribuível à característica fática (dispersão) da argamassa que une os sujeitos-titulares; por derradeiro, na esfera da reparação, ressarcibilidade indireta 
(os sujeitos individualmente não são aquinhoados com 0 quantum debeatur, que vai para um fundo).

Esses traços, atinentes ao direito difuso, e reconhecidos na proteção ao patrimônio cultural, implicam em relevantes consequências práticas de ordem jurídica, o que justifica a possibilidade de defesa do referido patrimônio cultural mediante instrumentos processuais como a ação civil pública; a imprescritibilidade das ações de reparação de danos ambientais coletivos.

\subsection{O patrimônio cultural no ordenamento jurídico brasileiro}

A regulamentação jurídica do patrimônio cultural brasileiro está previsto no artigo 216 da Constituição Federal de 1988, que estabelece que:

Art. 216. Constituem patrimônio cultural brasileiro os bens de natureza material e imaterial, tomados individualmente ou em conjunto, portadores de referência à identidade, à ação, à memória dos diferentes grupos formadores da sociedade brasileira, nos quais se incluem:

I - as formas de expressão;

II - os modos de criar, fazer e viver;

III - as criações científicas, artísticas e tecnológicas;

IV - as obras, objetos, documentos, edificações e demais espaços destinados às manifestações artístico-culturais;

$V$ - os conjuntos urbanos e sítios de valor histórico, paisagístico, artístico, arqueológico, paleontológico, ecológico e científico (BRASIL. Constituição, 1988).

No entendimento de Miranda (2006), a primeira observação a ser realizada é a de que a Constituição de 1988 reconhece que os bens culturais não se resumem apenas àqueles materializados em objetos físicos, mas também abrangem o chamado patrimônio cultural intangível ou imaterial, constituído por elementos, como tradições, folclore, saberes, línguas, festas, manifestações populares, entre outros, passando a receber expressamente a tutela do ordenamento jurídico brasileiro.

Como categorias de bens que integram o patrimônio cultural brasileiro, previstos nos incisos do artigo 216 da Constituição Federal pode-se destacar: as formas de expressão como grandes responsáveis pela transmissão de costumes, tradições e hábitos, razão pela qual são consideradas como poderosos instrumentos de divulgação da cultura (MIRANDA, 2006); os modos de criar, fazer e viver, que nada mais são 
que os hábitos, os costumes e as tradições do povo brasileiro, destacando a maneira de como se vive, abrangendo a culinária, agricultura, crenças, costumes, religião, entre outros; as criações científicas, artísticas e tecnológicas, bem como os espaços destinados às manifestações artísticoculturais, preservando desta forma, os espaços físicos tais como, cinemas, bibliotecas, museus, casas de cultura.

Tanto que o Decreto 3.551, de 4 de agosto de 2000 (BRASIL. Presidência da República, 2000), instituiu o registro de bens culturais de natureza imaterial, tornou possível a proteção dos bens culturais de natureza intangível, instituindo livros de registro de modos de expressão, saberes, celebrações. Neste sentido, necessário se faz compreender o que se entende por bem cultural, que segundo Souza Filho (1999, p. 42), "é aquele bem jurídico que, além de ser objeto de direito, está protegido por ser representativo, evocativo ou identificador de uma expressão cultural relevante". O referido autor ratificando esse entendimento, Souza Filho (1997, p. 18) coloca que:

[...] o bem cultural - histórico ou artístico - faz parte de uma nova categona de bens, junto com os demais ambientais, que não se coloca em oposição aos conceitos de pnvado e público, nem altera a dicotomia, porque ao bem material que suporta a referência cultural ou importância ambiental - este sempre público ou privado -, se agrega um novo bem, imaterial, cujo titular não é o mesmo sujeito do bem material, mas toda a comunidade. Este novo bem que surge da soma dos dois, isto é, do material e do imaterial, ainda não batizado pelo Direito, vem sendo chamado de bem de interesse público, e tem uma titularidade difusa, e talvez outro nome lhe caiba melhor, como bem sócio-ambiental, porque sempre tem de ter qualidade ambiental humanamente referenciada (SOUZA FILHO, 1997, p.18).

O reconhecimento da importância dos bens culturais, apresenta previsão legal no artigo 23, inciso IV, da Constituição Federal (BRASIL. Constituição, 1988), destaca o princípio da vinculação dos bens culturais, ao determinar a competência da União, Estados, Municípios e Distrito Federal para impedir a evasão de bens culturais, tendo em vista o elevado significado para a memória e identidade do povo brasileiro. Neste sentido, a proteção do Patrimônio Cultural, deve ser efetivada pelo poder público por previsão Constitucional, mediante ação popular, prevista no artigo 50, inciso LXXIII, ao alcance de qualquer cidadão, e pela Ação Civil Pública (BRASIL. Constituição, 1988), própria do Ministério Público prevista no artigo 129, inciso III. 


\section{Informação e patrimônio cultural: uma proposta de definição jurídica de informação patrimonial}

Sendo o patrimônio cultural regulado por instrumentos jurídicos específicos e por destacar também o seu caráter de bem cultural imaterial, e a necessidade de se reconhecer esse bem imaterial como patrimônio da humanidade, que torna possível uma análise do termo informação como objeto de reconhecimento dessa modalidade de patrimônio cultural, reconhecida na legislação pátria. Desta forma a Ciência da Informação fornece subsídios para que se torne possível a construção de um conceito de informação patrimonial, com base em aspectos culturais reconhecidos pela própria legislação.

\subsection{O termo informação}

Sendo o termo "informação" objeto da Ciência da Informação e de grande importância para a pesquisa, faz-se necessária um enfoque sobre a mesma, observando como o seu conceito pode instrumentalizar uma pesquisa que envolve o campo informacional.

$\mathrm{Na}$ palestra "Reflexões sobre a linha do Tempo", ministrada pela professora Henriette, da Universidade Federal da Bahia (GOMES, 2010), desde a "infância" da humanidade, os homens perceberam a necessidade de registrar conhecimentos de toda ordem. Com o tempo, os grupos sociais agregaram a necessidade de organizar essa informação registrada e de constituir meios eficazes para ter acesso ao conteúdo em qualquer tempo. O saber acumulado em milhares de anos, a partir da observação de fenômenos, passa a ser registrado através de vários suportes da informação. Os primeiros artefatos começaram a surgir a partir das raízes das práticas de três naturezas, quais sejam, museológicas, biblioteconômicas e arquivísticas.

Segundo a referida autora, dois comportamentos humanos estão presentes na raiz do desenvolvimento das três práticas: comunicacional, preservacionista e estabilidade cultural/social através da necessidade de sobrevivência. Por séculos, essas práticas foram desenvolvidas à luz de um conhecimento empírico. Mesmo na Roma antiga, observa-se a tentativa de organizar a informação. A referida informação começa a alcançar um novo status, agregando novos valores, fortalecendo a necessidade do registro do conhecimento acumulado a ser preservado. 0 usuário da informação ganha mais relevo, passando a acontecerem estudos sobre os comportamentos e as necessidades do usuário, serviços de disseminação e processos de mediação da informação.

O desenvolvimento científico e tecnológico que sucedeu a I Guerra Mundial passou a permear o capitalismo industrial deparando-se com o crescimento exponencial da informação, denominada de explosão da informação. O avanço da informação no último século tem sido evidente, sendo o termo informação percebido como um termo complexo, de múltiplas acepções e riquezas semânticas, para a Ciência da Informação. 
Os conceitos de informação foram determinados, segundo Capurro e Hjørland (2003), desde a tradução das palavras gregas informatio ou informo. Afirmam que, se a informação é historicamente construída, sendo ela que "dá forma a alguma coisa", é possível concluir que os sujeitos criam mecanismos informacionais (percepção, memória, imagem, entre outros) para reconhecer, interpretar e transmitir significados.

Em Capurro e Hjørland (2007), foi apresentada uma revisão do conceito de informação, explicando que, ao se usar o termo informação em Ciência da Informação, se deve ter em mente que informação é o que é informativo para uma determinada pessoa, e o que é informativo depende das necessidades interpretativas e habilidades do indivíduo. Devem-se considerar os dois contextos básicos nos quais o termo informação é usado: o ato de moldar a mente e o ato de comunicar conhecimento. Com relação aos usos modernos e pós-modernos da informação, o termo foi traduzido, primeiro, num contexto místico e, posteriormente, num sentido pedagógico geral. Contudo, os usos modernos do termo indicam um período de transição no qual o conceito ontológico medieval de moldar a matéria foi refeito sob premissas empíricas e epistemológicas.

No entendimento de Azevedo Netto (2008), com o desenvolvimento da área da Ciência da Informação, a informação passa a ligar os aspectos sócio-culturais ganhando espaço a criação de sistemas de informação voltados para as formas socioculturais de registro, usuário, disseminação e consumo, a partir de mecanismos informais de tratamento da informação.

A multiplicidade de contiguidades que o fenômeno informacional vem assumindo, conduz a percepção de uma forte tendência a ver a informação como fenômeno social. Verifica-se que a informação, enquanto fenômeno social, é que influencia e promove interação dos atores sociais, em diferentes níveis e estruturas (PINHEIRO; LOUREIRO, 1995).

No pensamento de Bentes Pinto (2007), a função social da informação, até final do século XIX, era reforçar o poder. No final do século XIX e início do século $X X$, a informação era utilizada como meio de desenvolvimento, no período entre guerras, por volta de 1934, proporcionando condições para gerar a paz, e, na década de 60, a informação apresenta-se como insumo da informação.

O objeto 'informação' segundo Mendel, apresenta:

[...] certa discrepância na forma que diferentes leis definem informação e/ou documentos. A definição essencial, normalmente, é aquela relativa ao tema central protegido pelo direito, seja "informação", "registros" ou outra coisa (como "informações oficiais"). Algumas leis, como é o caso da azerbaijana, apresentam definições múltiplas (no caso, de "informação", "informação privada" e "informação documentada"); algumas das quais não parecem, em sentido estrito, ter relevância (MENDEL, 2009, p. 148). 
Neste sentido, na maioria dos países, as suas respectivas leis definem o conceito de informação e/ou registros em acepção ampla, de modo a abarcar todas as formas possíveis de gravação de conteúdo: escrita, eletrônica ou por meio de outro sistema de armazenamento. Em certos casos, como o da Suécia e o do Japão, há exclusões específicas da definição de informação. De fato, a lei sueca emprega a definição de informação como uma espécie de substituto da exceção de processos deliberativos internos, estabelecendo que somente sejam considerados os documentos relativos a matérias já finalizadas sujeitos a determinadas exceções. O fato mais grave é que a exclusão de informações, na etapa de definição, significa que deixam de se aplicarem diversas salvaguardas, como as condições de dano a um interesse legítimo e a prevalência do interesse público, tão necessário ao considerem-se aspectos humanos.

Neste sentido, configura-se o entendimento de que a peculiaridade de cada estudo referente à informação produz efeitos específicos nas relações sociais em determinados grupos, tornando-os modelos de ações a partir de sua prática.

\subsection{Proposta de uma definição jurídica do termo "informação patrimonial"}

Apesar da tradicional divisão dos bens culturais em material e imaterial, em Miranda (2006), é colocado que os aspectos de materialidade e imaterialidade sempre se conjugam. Isto porque é colocado que o patrimônio cultural é constituído de três elementos, a saber, o meio ambiente, o conhecimento humano e os artefatos. No meio ambiente pode-se haver vários estágios entre a natureza virgem e a civilizada; o conhecimento humano é intangível, mas científico, incluindo todas as tecnologias, podendo ser tanto erudito quanto popular; e, os artefatos, são bens que o homem produziu fazendo atuar seus conhecimentos sobre o meio ambiente.

Silveira e Lima Filho (2005) colocam que é nesse sentido que é possível falar numa memória que impregna e restitui "a alma nas coisas", isto é, o objeto, enquanto expressão da materialidade da cultura de um grupo social, fortalece o vínculo com o lugar através da memória, que ao ser resignificada retoma lembranças de situações vividas outrora, bem como de seus vínculos com o seu lugar de pertença. Neste sentido, o objeto, portanto, fala sempre de um lugar, por estar ligado à experiência dos sujeitos com e no mundo, visto que ele representa uma porção significativa da paisagem vivida.

Tais reflexões apontam para aquilo que pode ser chamando de antropologia do objeto documental, por primeiro, ele materializar concepções culturais das mais diversas que, a partir dele, possibilitam a compreensão de outros domínios que concebem a cultura.

O que se processa é uma espécie de externalização das impressões internalizadas quando do contato com o "artefato", ou seja, a imagem do 
objeto e os sentidos possíveis que carrega consigo são interpretados, sendo revelados por meio das ações corporais, palavras e releitura pela arte, dos sujeitos queo observam, que revela sempre um observador atento do objeto.

Seguindo esse entendimento, esses aspectos tratados anteriormente, podem contribuir para a proposta deste artigo, levando-se em consideração que na maioria dos casos, o direito aplica-se a todas as informações, independentemente da finalidade para a qual são mantidas, existem particularidades que precisam ser analisadas para uma definição de informação patrimonial.

No Direito, as regras jurídicas foram adquirindo estrutura e valor próprio ao longo dos anos, fundamentando-se nas relações sociais, passando a uma exigência essencial e indeclinável de uma convivência ordenada entre os homens, de modo que a reciproca ubi jus, ibi societas, consiste na ideia de que não se pode conceber qualquer atividade social desprovida de forma e garantia do direito. A informação, assim como o direito, está pressuposta em cada ação do homem que se relacione com outro homem, não existindo senão na sociedade, uma vez que, segundo Azevedo Netto (1999), a informação seria entendida como um signo que, quando percebido pelo receptor, provocaria uma alteração na sua estrutura, seja ela física, psíquica ou cognitiva. Desta forma, a informação teria a sua definição situada no receptor dela própria, já que é o receptor que pode dar noção da existência da informação ou não. O autor afirma ainda que "a origem do sinal que forma a noção de informação, necessariamente não precisa ser humana" (AZEVEDO NETTO, 1999, p. 138). Desse modo, a informação estaria transitando por diversos meios distintos: natureza, cultura e técnica, mas só se efetivando como informação quando reconhecida pelo seu receptor humano.

Igualmente, vendo a informação a partir do mundo construído, daquilo que o homem acrescenta à natureza, através do conhecimento de suas leis, nas relações interpessoais onde ocorre transmissão ou disseminação da informação, e sendo o direito quem regula todas as formas de relações humanas, pode-se dizer que para o direito:

[...] a informação pode ser compreendida como um fenômeno jurídico implícito em cada comportamento do homem, externalizado através de uma mensagem, que o receptor recebe e reproduz, assumindo forma ou estado individualizado da matéria, incorporando-a e moldando-a em cada ramo do direito que a definir em suas respectivas particularidades (SOUSA, 2012, p. 32).

Neste sentido, a autora coloca que o conceito jurídico de informação se funda sobre dois aspectos: o primeiro, implícito, que depende da relação entre o sujeito e o signo (informação), em que este depende da relação entre sujeitos, e o segundo, explícito, que se externaliza num 
movimento dialógico da comunicação, de modo que a mensagem é mediada pela linguagem.

A informação é elemento basilar da comunicação, e para Oliveira, "O uso que fazemos de uma palavra e a compreensão que temos dela, estão imbricadas ao conceito que temos de um objeto, e esse fenômeno é contextual, depende de um referencial espacial, temporal e cultural" (OLIVEIRA, 2010, p. 52).

O homem é animal cultural, e a cultura é quem delimita a forma de informação, sendo esta, compreendida como elemento social, que existe dentro da sociedade e está subordinado dentro da cultura que a produz. Com esse fundamento, é possível estabelecer subcategorias que se apresentam conexas, entre patrimônio cultural, os instrumentos jurídicos de sua proteção, e a informação, capazes de contribuir para uma definição de informação patrimonial, que possibilite abranger tanto o patrimônio cultural material como o imaterial.

O simbolismo, como categoria do pensamento, está muito presente no aspecto de preservação do patrimônio cultural e ao mesmo tempo, para a informação é o signo numa dimensão lógica, em que a informação passa a ser compreendida como a dimensão material do signo.

A coletividade, em que tanto a informação quanto o patrimônio cultural só se reconhecem no âmbito das relações sociais, e nas trocas de experiência. Segundo Gonçalves (2005), os patrimônios podem exercer uma mediação entre os aspectos da cultura classificados como "herdados" por uma determinada coletividade humana e aqueles considerados como "adquiridos" ou "reconstruídos", resultantes do permanente esforço no sentido do auto aperfeiçoamento individual e coletivo, em que o seu sentido fundamental consiste talvez em sua natureza total e em sua função eminentemente mediadora.

A cultura, em que o termo tal como é empregado vivencia os princípios europeus em todos os sentidos, e é utilizado a partir de duas vertentes: na perspectiva da (civilization) civilização em que se escondia numa ideia evolucionista de que o homem iria do pior para o melhor e tinha estágios civilizatórios, e a partir da ideia de "UR" que se aproxima no grego Arché (saber da origem). Posteriormente, passa a ser compreendida como "tudo aquilo que possui a intervenção antrópica", considerando como cultura o "construído", e a natureza o "dado". O termo cultura vai ser utilizado sempre como elemento sobre qual se vai fundar todas as análises do humano e do não-humano. Adam Kuper (2001) descreve a cultura como domínio de configuração simbólica e a considera um elemento determinante da natureza humana. A questão simbólica é essencial à compreensão social. Nesse sentido, a cultura é compreendida por meio de três elementos: o sujeito, o objeto e o contexto simbólico, de modo que, a ação coletiva é organizada por meio de sistemas simbólicos.

Todo o comportamento humano é, neste sentido, "artificial" e não "natural". Então Cultura passa a ser compreendida como a criação, transmissão, reformulação e transformação desses ambientes artificiais. 
Deve-se definir patrimônio em termos de significado que tem para a população em geral, no entendimento de que o significado de um bem cultural depende da forma em que é utilizado na sociedade (DURHAN, 2013). E a informação seria um canal capaz de proporcionar a disseminação dessa cultura na sociedade.

A identidade, construída a partir das vivências, e memória a partir de uma construção seletiva do passado. Para Lévi-Strauss (1976) dessas reflexões surge o debate sobre identidade cultural que não se restringe ao âmbito privado, mas coletivo. A busca por essa identidade é uma luta existencial, desesperada pelo reconhecimento e manutenção de um estilo de vida que pode durar apenas um espaço de tempo. Muitas vezes essa busca se dá em meio ao enculturamento considerado pelo autor como processo de cultivação do ser humano, desde o nascimento (endoculturado) pelas formas culturais presentes na dimensão social em que está inserido, sob a influência do caráter psicológico.

A seletividade, pela vida cultural, se constituir de natureza extremamente mutável e dinâmica, torna-se necessário uma seletividade da atuação preservacionista em que a flexibilidade do objeto torna-se relevante por ser o próprio meio social que tornará determinado bem cultural reconhecido, sujeito a preservação ou não. Do mesmo modo ocorre com a informação, que pode ser considerada importante ou não dependendo da necessidade do receptor que recebe a mensagem do emissor.

A individualização do objeto, conforme a doutrina italiana, quando reconhecida pelo poder público pode ser considerada como bem cultural formal, quando não, como bem cultural real. Desse modo, exige um valor incorporado reconhecidamente pela comunidade que só se efetiva a partir de um interesse judicial que o reconhece e passa a regêlo através de instrumentos jurídicos especiais que o diferencia dos demais bens. Importante se faz destacar, segundo Miranda (2006, p. 57), "o patrimônio cultural, enquanto bem jurídico, não se confunde com o objeto físico, visto que os direitos são sempre bens incorpóreos e a divisão classificatória de bens em materiais e imateriais referem-se aos objetos de tais direitos".

Neste contexto, pode-se dizer que Informação Patrimonial é a mensagem transmitida de um emissor para o receptor, que é reconhecida através de grupos sociais através de aspectos culturais desenvolvidos a partir de influencias políticas, sociais, econômicas ou até mesmo jurídicas que enquanto relevantes se perpetuam. Pode ser considerada Informação patrimonial, (assim como o patrimônio cultural que para ser considerado como tal, precisa ser reconhecido), aquela que é reconhecida pela comunidade. Varia seu reconhecimento a partir dos aspectos culturais que o determinam em virtude de não se levar em consideração sua materialidade ou imaterialidade. Cultural, porque além da ideia que determina o patrimônio material, a partir da ideia de propriedade, a imaterialidade considerada para a informação patrimonial, depende de seu reconhecimento e 
aceitação que se dá pela internalização da mensagem transmitida pelo emissor e internalizada pelo receptor no contexto social em que está inserido.

\section{Considerações finais}

Percebe-se que o patrimônio cultural brasileiro em sua regulamentação jurídica envolve aspectos do patrimônio material e imaterial, cuja principal proteção está prevista no artigo 216 da Constituição Federal (BRASIL. Constituição, 1988). Muito ainda se tem a explorar a esse respeito, com o objetivo de preservação de bens culturais e sua transmissão a gerações futuras.

Na compreensão de uma proteção ao referido patrimônio, destacouse a importância de situa-lo dentro de uma geração de diretos fundamentais, entre os quais estão os direito difusos, que pertence a coletividade e não pode ser individualizado.

O patrimônio imaterial em sua complexidade possibilita a análise de vários aspectos que possibilitam influenciar na construção de uma definição de informação patrimonial que contemple ambas asespécies de patrimônio. Neste sentido, são justamente suas subcategorias que de forma conexa viabilizaram um caminho a ser aprofundado no sentido de que essa definição abre novas possibilidades de ampliação.

\section{Referências}

AZEVEDO NETTO, C. X. Uma face da ciência da informação. In: PINHEIRO, L. V. R. Ciência da informação, ciências sociais e interdisciplinaridade. Brasília; Rio de Janeiro: IBICT, 1999. p. 133-141.

AZEVEDO NETTO, C. X. Informação e patrimônio arqueológico: formação de memórias e construções de identidades. In: ENCONTRO NACIONAL DE PESQUISA EM CIÊNCIA DA INFORMAÇÃO - ENANCIB, 9., São Paulo, 2008. Anais... São Paulo: ENANCIB, 2008. p. 1-12.

BENJAMIN, A. H. V. A insurreição da aldeia global contra o processo civil clássico apontamentos sobre a opressão e a libertação judiciais do meio ambiente e do consumidor. In: MILARÉ, E. (Coord.). Ação civil pública: lei 7347/85, reminiscências e reflexões após dez anos de aplicação. São Paulo: Revista dos Tribunais, 1995. p. 71-151.

BENTES PINTO, V. Interdisciplinaridade na ciência da informação: aplicabilidade sobre a Representação indexal. In: BENTES PINTO, V.; CAVALCANTE, L. E.; SILVA NETO, C. (Org.). Ciência da informação: abordagens transdisciplinares gêneses e aplicações. Fortaleza: UFC, 2007. V. 1 , p. 105-142.

BRASIL. Constituição (1988). Constituição da República Federativa do Brasil. Brasília, DF: Senado Federal; Centro Gráfico, 1988.

BRASIL. Presidência da República. Decreto 3.551, de 4 de agosto de 2000. Institui o Registro de Bens Culturais de Natureza Imaterial que constituem 
patrimônio cultural brasileiro, cria o Programa Nacional do Patrimônio Imaterial. Diário Oficial da União, Brasília, 4 ago. 2000. 2000. Disponível em: <http://www.planalto.gov.br/ccivil_03/decreto/D3551.htm>. Acesso em: 6 jan. 2014.

BRASIL. Presidência da República. Lei no 8.078, de 12 de setembro de 1990. Dispõe sobre a proteção do consumidor e dá outras providências. Diário Oficial da União, Brasília, 12 set. 1990. Disponível em: $<$ http://www.planalto.gov.br/ccivil_03/leis/L8078compilado.htm >. Acesso em: 6 jan. 2014.

CAPURRO, R.; HJØRLAND, B. The concept of information. Arist: Annual review of information science and technology, New York, v. 37, p. 343$411,2003$.

CAPURRO, R; HJØRLAND, B. O conceito de informação. Perspectivas em Ciência da Informação, Belo Horizonte, v. 12, n. 1, p. 148-207, jan./abr. 2007.

DURHAN, E. R. Reflections on culture, heritage and preservation. Vibrant, Virtual Braz. Anthr, Brasília, v. 10, n. 1, p. 77-94, jan./jun, 2013.

GONÇALVES, J. R. S. Ressonância, materialidade e subjetividade: as culturas como patrimônios. Horiz. Antropol., v. 11, n. 23, p. 15-36, jan.jun. 2005.

GOMES, H. F. Fundamentos da ciência da informação: reflexões sobre a linha do

tempo, 24 mar. 2010. 22f. [Notas de Aula].

KUPER, A. Cultura: a visão dos antropólogos. Baurú: EDUSC, 2002.

Natureza e cultura. In: LÉVI-STRAUSS, C. (Org.). As estruturas elementares do parentesco. Petrópolis: Vozes,1976. p. 41-49.

MENDEL, T. Liberdade de informação: um estudo de direito comparado. 2. ed. Brasília: UNESCO, 2009.

MIRANDA. M. P. de S. Tutela do patrimônio cultural brasileiro: doutrina, jurisprudência, legislação. Belo Horizonte: Del Rey, 2006.

NOVELINO, M. Direito constitucional. 4. ed. São Paulo: Método, 2010.

OLIVEIRA, H. P. C. de. Afrodescendência, memória e tecnologia: uma aplicação do conceito de informação etnicorracial ao projeto "A Cor da Cultura". 2010. 139f. Dissertação (Mestrado em Ciência da Informação) Universidade Federal da Paraíba, João Pessoa, 2010.

PINHEIRO, L. V. R.; LOUREIRO, J. M. M. Traçados e limites da ciência da informação. Ciência da Informação, Brasília, v. 24, n. 1, p. 1-19, abr. 1995.

SARLET, I. W. A eficácia dos direitos fundamentais. Porto Alegre: Livraria do Advogado, 1998. 
SILVEIRA, F. L. A. da; LIMA FILHO, M. F. Por uma antropologia do objeto documental: entre a "a alma nas coisas" e a coisificação do objeto. Horiz. Antropol., v. 11, n. 23, p. 15-36, jan-jun 2005.

SOUSA, R. P. M. de. Memória exercitada: o direito de acesso a informações no âmbito dos arquivos permanentes. 2012. $116 \mathrm{f}$. Dissertação (Mestrado em Ciência da Informação) - Universidade Federal da Paraíba, João Pessoa, 2012.

SOUZA FILHO, C. F. M. de. Os direitos invisíveis. In: OLIVEIRA, F. de; PAULI, M. C. (Org.). Os sentidos da democracia: políticas do dissenso e hegemonia global. Rio de Janeiro: Vozes, 1999. p. 307-334.

SOUZA FILHO, C. F. M. de. Bens culturais e proteção jurídica. 3. ed. Curitiba: Juruá, 1997. 